\title{
Outbreak Investigation of Diarrheal Diseases in Jajarkot
}

\author{
Bhandari GP, ${ }^{1}$ Dixit SM, ${ }^{2}$ Ghimire U, ${ }^{1}$ Maskey MK ${ }^{1}$ \\ ${ }^{1}$ Nepal Health Research Council, ${ }^{2}$ Center for Molecular Dynamics Nepal
}

\begin{abstract}
Background: Diarrhea is a major public health problem in Nepal. Recently, there was an outbreak of diarrheal diseases in different districts of mid and far western region of Nepal and the most affected district was Jajarkot. The objective of this study was to detect the causative organism and analyze the epidemic outbreak patterns of diarrhea in selected health institutions in Jajarkot district, Midwestern Region of Nepal, in terms of their demographic characteristics and laboratory findings of stool specimens.

Methods: A descriptive study was conducted using secondary data from health institutions of two Village Development committees of Jajarkot. Stool samples were collected purposively to identify the agents of diarrheal diseases.

Results: Out of the total 13 stool samples tested, 5 were diagnosed as harboring Vibrio cholerae. The Attack Rate and Case Fatality Ratio were calculated to be $8.2 \%$ and $1 \%$ respectively for the District. Age groups 15-44 were highly affected; male and female were approximately equally affected.

Conclusions: Cholera appears to have been the most important cause for mortality in Jajarkot diarrhea outbreak. The diarrhea outbreak in any districts of Nepal should be closely monitored for the possibility of a Cholera epidemic in the future.

Key words: cholera, diarrhea, epidemic, outbreak.
\end{abstract}

\section{INTRODUCTION}

Diarrhea is a major public health problem in Nepal. It is characterized by the passage of three or more loose or liquid stools per day, or more frequently than is normal for the individual. ${ }^{1}$ The infection may be spread through contaminated food or drinking-water, or from person to person as a result of poor hygiene. ${ }^{1}$ It is an important cause of morbidity and mortality in many regions of the world, with more than 4 billion cases and 2.5 million deaths estimated to occur annually. ${ }^{2}$

Intestinal infection with $V$. cholera results in the loss of large volume of watery stool leading to severe and

rapidly progressing dehydration and shock. Without adequate rehydration therapy severe cholera kills about half of affected individuals. ${ }^{2}$

Recently, there was an outbreak of diarrheal diseases in Jajarkot, mid-western region of Nepal. The objective of this study was to detect the causative organism and analyze the epidemic outbreak patterns of diarrhea in selected health institutions in Jajarkot district, in terms of demographic characteristics and laboratory findings of stool specimens.

Correspondence: Dr. Gajananda Prakash Bhandari, Nepal Health Research Council, Ramshahpath, Kathmandu, Nepal. Phone: 9849077000, Email: gpbhandari@ gmail.com. 
Outbreak Investigation of Diarrheal Diseases in Jajarkot

\section{METHODS}

A descriptive study was conducted using secondary data from two health institutions of Jajarkot district from middle of the March to July 2009. The purposive sample of stool and demographic data were collected from Khalanga District Hospital and Khagenkot (Dalli) health post. The stool sample were collected in Cary Blair Transport Media and brought to the National Public Health Laboratory, Kathmandu, for further microbiological analysis. The demographic profile of were entered using Microsoft Excel 2003. The statistical analysis was done in Statistical Package for Social Science version 13.0 for windows.

\section{RESULTS}

The total number of cases $(n=425)$ admitted to District Hospital, Khalanga from mid-march 2009 to mid-July 2009 were analysed.

The first four weeks starting from third week of March 2009 indicate a steady rise in morbidity with no reported cases of mortality. However, from the first week of April 2009 the morbidity trend increased and reached up to 41 cases in mid May. There was steady trend of low morbidity and mortality till the second week of June with sudden increase in morbidity and mortality from third week of June. The morbidity was increasing by the end of July, whereas mortality trend was decreasing. The maximum number of morbidity cases (97) was recorded in the second week of July 2009. In terms of mortality, the peak of 38 cases was observed in the second week of July 2009 (Figure 1).

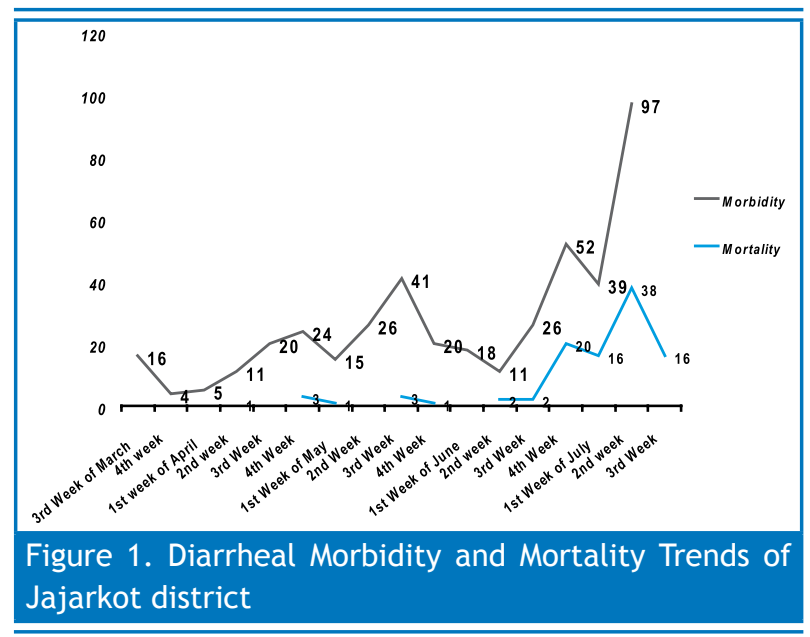

Stool samples from district hospital, Khalanga and Dali health post were collected and tested in Nepal Public Health Laboratory. Out of the total 13 samples tested, 5 were diagnosed as harboring Vibrio cholerae $(V$. cholerae 01 biotype El Tor serotype Ogawa) (Table 1).

\section{Table 1. Organisms detected in the stool sample}

\begin{tabular}{|llc|}
\hline SN & Organism & No (\%) \\
\hline 1 & Vibrio cholerae & $5(38.46)$ \\
2 & E. coli & $3(23.07)$ \\
3 & Salmonella & $1(7.69)$ \\
4 & None & $4(30.76)$ \\
\hline
\end{tabular}

Out of the total of $\mathbf{4 2 5}$ morbidity cases as registered in DHO hospital Khalanga, 58\% were male and $42 \%$ were female. Likewise at Dalli Health post, out of 453 morbidity cases, $53 \%$ were male and $47 \%$ were female.

The reproductive age group (15-44 years) appeared to be the most affected by the diarrhoeal outbreak. In DHO hospital, $65 \%$ percent of 15-44 age group were diarrhoeal cases, while in Dali health post, $53 \%$ of similar agegroup was admitted with diarrhoeal symptoms. Children appeared to be the least affected group with only $0.2 \%$ at DHO hospital (Table 2).

Table 2. Age wise distribution of diarrhea cases in
Jajarkot
\begin{tabular}{ccc|} 
Age group & DHO Khalanga (\%) & Health Post Dalli (\%) \\
\hline $0-4$ & $1(0.2)$ & $51(11)$ \\
$5-14$ & $119(28)$ & $87(19)$ \\
$15-44$ & $275(65)$ & $242(53)$ \\
$45-59$ & $20(5)$ & $32(7)$ \\
$\geq 60$ & $10(2)$ & $41(9)$ \\
Total & 425 & 453 \\
\hline \hline
\end{tabular}

Jajarkot district is widely inhabited by Dalit group (ethnic code 1), Disadvantaged group (ethnic code 2 ) and Upper Caste group (ethnic code 6). Table 3 shows that out of the total number of patients visiting the district hospital, majority (49\%) were of the Upper Caste group (Brahmin, Chhetri, Thakuri etc) while at the Dalli Health Post the majority of the affected population appeared to be of the Dalit group (50\%). Disadvantaged group also appeared to be in the higher-affected category at both sites.

From the diarrhea mortality and morbidity data provided by the district health office for the Jajarkot district as a whole, the attack rate (AR) was calculated to be $8.2 \%$ and case fatality ratio (CFR) was $1 \%$ (number of cases 12,500 , deaths 128 , Jajarkot population - 151,551). The most affected VDCs in terms of mortality were Majhkot and Kortang where number of deaths was 19 and 16 respectively. As reported, only 10 deaths out of 128 occurred in the health institution, which suggests that patients with access to public health institutions were less likely to die from diarrhea. 
Outbreak Investigation of Diarrheal Diseases in Jajarkot

\begin{tabular}{lcc} 
Table 3. Ethnicity wise distribution of diarrhea cases in Jajarkot & & \\
\hline Ethnicity & DHO Khalanga (\%) & Health Post Dalli (\%) \\
\hline Dalit & $143(34)$ & $228(50)$ \\
Disadvantaged Janajatis & $64(15)$ & $79(17)$ \\
Disadvantaged non-dalit Terai caste groups & $11(3)$ & $2(0.4)$ \\
Relatively advantaged Janajatis & $1(1)$ & $1(0.2)$ \\
Upper caste groups & $206(49)$ & $143(32)$ \\
Total & 425 & 453 \\
\hline
\end{tabular}

\section{DISCUSSION}

Clinical presentation of extensive watery loose motion, vomiting and rapid dehydration of diarrhea cases leading to death in a short time had raised suspicion about the possibility of cholera infection in Jajarkot and Midwest diarrhea epidemic. To find around $40 \%$ ( 5 out of 13) stool samples positive for Cholera imparted a strong suggestion to consider Jajarkot diarrhea as a case of Cholera epidemic. This initial finding was substantiated later by further detection of Cholera organisms from the stool samples collected from Jajorkot, Rukum and Dailekh during the preparation of the article.

Cholera continues to be major public health problem despite the fact that the public health aspects of the disease were described in detail over a century ago. ${ }^{3}$ Tamang et al reported 46 laboratory confirmed $V$. cholerae cases out of 148 cases of watery diarrhoea $(31 \%)$, which was conducted in a hilly district Kavre. ${ }^{4}$ In this study, only strain 01 (El Tor, Ogawa) was reported. This is also reflected in our findings where Vibrio cholera 01 biotype El Tor serotype Ogawa was found to be the predominant strain.

Shrestha et al reported outbreak of Cholera in a similar seasonal period, but with higher isolation rate of $V$. cholerae. ${ }^{5}$ Our investigation showed that the peak morbidity and mortality was from mid June to mid July. Similar observation have been shown by Shrestha et al. ${ }^{6}$ Kansakar et al reported V. cholerae $01 \mathrm{El}$ Tor Ogawa responsible for cholera outbreak in Kathmandu Valley. ${ }^{7}$

All these findings from different studies carried out in Kathmandu Valley, Kavre District and Jajarkot District confirm the presence of $V$. Cholerae in respective outbreaks. This suggests that cholera outbreaks are likely to continue to occur in coming years. Therefore, a reliable and rapid response mechanisms needs to be put in place for all future epidemics in terms of a Epidemiology and Lab-based surveillance system.

These health institutions were selected purposively because most of the other health institutions of the district were inaccessible and hence data sampling was not considered feasible. A more robust and systematic research on the outbreak would lead to more closer finding in an outbreak in our context.

\section{CONCLUSIONS}

Diarrhea remains a major public health problem in Nepal. Its lethal potential in underdeveloped, remote and malnourished population should not be undermined. Cholera appears to have been the most important cause for mortality in Jajarkot diarrhea outbreak.

In view of detection of cholera organism as in previous outbreaks in different districts of Nepal, the diarrhea outbreak in any districts of the country should be closely monitored for the possibility of a cholera epidemic. Cholera is likely to continue to take death tolls in diarrhea outbreaks in coming years. Therefore a reliable and rapid response mechanism should be in place for all future outbreaks. An Epidemiology and Laboratory based surveillance system is strongly recommended.

\section{REFERENCES}

1. World Health Organization . Diarrhea: The treatment of diarrhea. [Online]. [cited 2009 Sept 29]. Available from: URL: http:// www.who.int/topics/diarrhoea/en/.

2. Sac DA, Sac RB, Nair GB, Siddique AK. Cholera. Lancet. 2004;363:223-33.

3. Shears P. Recent development in cholera. Curr Opin Infec Dis. 2001;14:553-8

4. Tamang MD, Sharma N, Makaju RK, Sarma AN, Koju R, Nepali $\mathrm{N}$, et al. An outbreak of El Tor cholera in Kavre district, Nepal. Kathmandu Univ Med J. 2005;3(2):138-42.

5. Shrestha AD. Cholera in Kathmandu Valley:How prevalent is it?. J Nepal Med Assoc. 1991;29:193-6.

6. Sherstha C, Thapa M, Oda Y, Subba L, Dhakhwa JR. Outbreak of cholera in Kathmandu Valley. J Nepal Med Assoc. 1997;35:66-9.

7. Kansakar P, Malla S, Ghimirey G. Cholera outbreak in Kathmandu valley in 2004: A review of National Public Health laboratory findings. J Nepal assoc Med Lab Sciences. 2005;7:20-3.

8. Karki A, Tiwari BR. Prevalence of Acute Diarrhoea in Kathmandu Valley. J Nepal Med Assoc. 2007;46(168):175-9. 